\title{
Hfrocubanidad y americanidad: construcción visual de imágenes y palabras en la obra de José Bedia ${ }^{1}$
}

\author{
María Teresa Acosta Carmenate \\ Doctorado Interinstitucional en Arte y Cultura \\ Universidad de Guanajuato, México \\ https://orcid.org/0000-0002-3923-1565 \\ acostadelarte@gmail.com
}

\section{Resumen}

El dilema del que estudia el arte africano, incluso sus influencias en las creaciones trasatlánticas, es el enfrentamiento a la imagen y todo lo que importa en la constitución del objeto o de los objetos. Es encomiable la labor de algunos artistas cubanos contemporáneos como José Bedia, que, en el conocimiento del poder de la palabra, se ubica en los orígenes africanos de la oralidad y crea una relación imagen-palabra que permite descubrir otras posibles realidades, que no son fáciles de ser atrapadas en la omnipresencia de la visualidad. Bedia se reconoce dentro de un espacio determinado por lo transcultural. Es, al decir de Orlando Hernández, que siendo Bedia: "Proveniente de una cultura, la cubana, acostumbrada a la reverencia y al maltrato en su diaria relación con los dioses no le resulta trabajoso [...] continuar en el arte con esa misma familiaridad" (27). La relación de las palabras y las imágenes en la obra de José Bedia no están vinculadas únicamente con los problemas planteados sobre esto desde la postura eurocéntrica, sino también con el modo en el que se entiende esta relación, tanto en aquellas prácticas trasatlánticas de influencia africana como en las culturas nativas americanas.

Palabras clave: arte africano; José Bedia; palabras; imagen; lo transcultural.

\section{Afrocubanity and Americanity: visual construction of images and words in the work of José Bedia}

\section{Hbstract}

Facing the dilemma of the one who studies African Art, including its influences on trasatlantic creations, is the confrontation with the image and everything that matters in the constitution of the object or objects. The work of some cuban contemporary artist such as José Bedia is

\footnotetext{
1 Procedencia del artículo: Este artículo proviene del trabajo de investigación en el doctorado que cursa la autora: Doctorado Interinstitucional en Arte y cultura, adscrita, a la universidad de Guanajuato, México.
} 
commendable, who in understanding the power of the Word, even locating himself in the African origins of orality, creates an image-word relationship that allows us to discover other possible realities, which are not easy to be caught in the omnipresence of visuality. Bedia is recognized within a space determined by the cross-cultural. It is, according to Orlando Hernández, that being Bedia: "Coming from a culture, the Cuban, accustomed to reverence and mistreatment in her daily relationship with the gods, does not find it difficult [...] to continue in art with that same familiarity." (Hernández 27). The relationship between words and images in José Bedia's work is not only related to the problems raised on this from the Eurocentric position, but also to the way in which this relationship is understood, both in those trasatlantic practices of African influence and in the native American cultures.

Keywords: contemporary art; José Bedia; words; image; Afro-cubanity.

Recibido: 15 de abril del 2020.

Reflexión

https://doi.org/10.25100/poligramas.v0i51.10852

\footnotetext{
¿Cómo citar este documento en MLA? - How to quote this document in MLA?

Acosta Carmenate, María Teresa. "Afrocubanidad y americanidad: construcción visual de imágenes y palabras en la obra de José Bedia" Poligramas 51 (2020): n. pag. Web. Fecha de acceso (día, mes en mayúscula y abreviado, y año).
}

Europa, México y Haití son tres puntos geográficos en la fisonomía de lo posnegro de las artes visuales cubanas. La repetición de «motivos» ha variado formalmente desde la primera mitad del siglo XX a la fecha, pero se ha conservado como adjunto en los autores que han trabajado con la temática afrocubana (distíngase la obra de José Bedia). Algunos de estos elementos recurrentes son: el diablito - propio de la sociedad secreta masculina Abakuá (también conocidos como ñáñigos)-, collares, altares, cazuelas con contenidos vegetales, imágenes católicas, velas, animales como gallos y gallinas - propios de la liturgia afrocubana-, caracoles, tabaco, otras sociedades o majas (serpientes) (De Juan 166). 
Es relevante mencionar que la caña de azúcar, como muchas otras cosas que nadie había visto antes como «motivos» dentro del trabajo de la imagen, se encuentra en la fotografía de la italiana Tina Modotti, que laboró en México, de 1923 a 1929, captando imágenes que rebasaron el contexto mexicano y simbolizaron a la geografía americana. Los «motivos» en la obra de Modotti alimentaron la «americanidad» y la construcción de identidades visuales en la pintura cubana, más allá de su relación amorosa con el revolucionario cubano Julio Antonio Mella, quien fue asesinado en México. A Tina, junto a Gerardo Murillo (Dr. Atl), y no de la misma manera, es posible considerarla una precursora del rescate del arte popular en México y de su estética, gracias a imágenes que, a modo de una fotografía antropológica, no solo muestran objetos como: jícaras, trompos, juegos, artesanos, etc. Si bien, en 1921, el Dr. Atl, en el libro Las Artes Populares en México, teorizaría sobre la estética de este arte, Tina haría lo propio con la imagen y detallaría la diferencia, intuyendo así las categorías de esa estética que se asoma desde una producción propia en un determinado entorno o espacio.

El trabajo del «motivo» de la caña de azúcar en la obra de Modotti, y su propia reflexión sobre la estética popular, es un antecedente considerable para el trabajo simbólico de dicho «motivo» en la pintura cubana, como también su presencia como image. Es sobrentendido el trazado de este en la obra de Wifredo Lam como constructo de los «motivos» que acompañan a la temática afrocubana en la pintura, que evoluciona hacia la imagen de los bosques de Marabú bedianos, no solo en palos sagrados de la santería y el Palo Mayombe, sino como paisaje común, trasatlántico y enmarañado de la naturaleza cubana.

En el Centro de Arte de Puerto Príncipe, Haití, en el año 1945, lo afrocubano hace presencia. Entre muchos, expondrá Carlos Enríquez, que, a diferencia de otros, toma apuntes en el Museo Etnográfico de Puerto Príncipe, donde queda explícita la influencia del vudú en el arte haitiano. Entre 1991 y 1992, la Casa de las Américas mostraría por primera vez estos esbozos. El «llamado haitiano», como pudiera decirse, modificaría la visión de lo geocultural en el arte cubano y llevaría de la mano a otros artistas de esta posvanguardia a pensarse a sí mismo y mostrar una image muy particular. En este contexto, surge la obra Caridad del Cobre (1946) de Roberto Diago y El reino de este mundo (1949), de Alejo Carpentier, en la cual planteó la categoría estética de lo «real maravilloso».

Cada uno de estos «motivos» conformarán, más adelante, otros antecedentes y la propia disposición de la temática mencionada hasta la actualidad. Algunos ejemplos de ello pueden 
observarse, desde 1933, en la obra de Carlos Enríquez; en el trabajo de René Portocarrero, ya en los años sesenta; en la exploración simbólica de las colografías de Belkis Ayón, donde la importancia de las grafías llamadas Ekeniyó y la representación del Íreme ("diablito») no tendrán, en los años ochenta y noventa, un sentido folclórico, sino un carácter simbolista de su sentido gemelar, a través de Aberiñán y Aberisún, y su propia visualidad del antepasado. Este Íreme o "diablito», que también presenta Ayón, solo posee ojos y no boca, porque la palabra está relacionada con la imagen mental, dentro de la genealogía de Thomas Mitchell (Thomas Mitchell W. J., 1986), y dicha palabra se provoca en la corporalidad. El trabajo de 1992, Obí Omí Tuto, de Santiago Rodríguez Olazábal, plantea otras recreaciones de grafías en la imagen visual de la plástica contemporánea cubana con estos apegos. Por otro lado, José Bedia, sin inclinaciones a lo ñáñigo, ha proyectado visualmente el juego histórico con representaciones de Papa Legba, representación vudú, que es análoga a Elegguá en las religiones afrocubanas y que se ha confundido con el diablo. Sus modos de representación en países como Haití y la propia Cuba se dan a través de los veves, símbolos gráficos efímeros que se pintan con harina, ceniza, polvo de ladrillo, etc., sobre el piso, al modo de taínos y congos, que Bedia recrea no solo como un «motivo» más, sino como parte de su reflexión histórica dentro del ámbito americano.

Sobre esto profundiza Mitchell, acercándose al problema del lenguaje y las imágenes, al margen de lo que los ilustrados del siglo XVIII determinarían sobre esta materia, cuando fundamentaban que tanto las imágenes como las palabras permiten el entendimiento o la clarificación de la realidad. Por otro lado, en Bedia, como establece Kevin Power: "[...] su contexto cultural híbrido y fluido del caribe, del cual es parte y producto" (125), permite también la comprensión de lo que es la imagen en África subsahariana, una herencia visualmente idéntica que equipara la figura a la palabra. La ausencia durante muchos siglos en el continente africano de la escritura fonética le remitió importancia a incisiones y pinturas sobre superficies que varían desde la roca al cuerpo. Sobre el suelo, algunas culturas, como los yorubas o los dogones, trazan grafías y formas geométricas similares a ideogramas que no diferencian la imagen de la escritura.

La codificación y la movilidad de esos signos o estas tradiciones de lenguaje jeroglífico es parte de las estructuras que se agregan como herencia en las diásporas; de ahí que encontremos en su trabajo la presencia de variados elementos extraídos de la santería o Regla de Ocha y del Palo Mayombe, de la que Bedia es practicante. Iván Bargna ha referido que: "[... ] 
las culturas africanas han elaborado una profunda reflexión sobre el status de la palabra [...] que nos permite hablar de una concepción africana de la palabra" (45). Es posible visualizar asimismo sus temas amerindios a través de figuras y léxicos, no solo utilizando ideas sino también el lenguaje, en los que son recurrentes las pipas humeantes de los American Indians (o el tabaco) y la lengua taina. Así mismo, Bedia ha tenido estancias de aprendizaje con chamanes de forma recurrente y participación ritual que ha transformado o mutado ciertas formas en su obra.

Entre 1980 y 1984, Crónicas americanas ha sido un importante documento visual que Omar-Pascual Castillo ha relacionado con la manera en la que se realiza una bitácora, lo que nos faculta para hablar de «bitácora pictórica»². Este tipo de trabajo, a nivel de la imagen, permite la institución de su documento visual, construido desde una estructura investigativa plástica, ya que sus registros pueden interpretarse como apuntes, como un diario de viaje, como las ideas esbozadas dentro de la metodología de trabajo que puede utilizar un antropólogo, un etnógrafo, un arqueólogo o, incluso, artistas como Jan Hendrix o Miguel Ángel Blanco, que han trabajado desde su propia idea de clasificación de diversos elementos naturales, relacionados con sitios muy específicos como la selva Lacandona o Desierto de la Soledad, en México -en el caso del primero-, y la de Guadarrama, en España -en el caso del segundo-, para construir su propia naturaleza sobre superficies, a manera de ideogramas.

Por otro lado, tampoco se puede evadir la obra de Ana Mendieta, expuesta a las culturas aborígenes y las formas del arte originario, en las cuales conceptos e ideas vinculados con «raíz» o "despojo» no consienten obviar su trabajo in situ. Sus improntas, desde y en la naturaleza, como en Jaruco, La Habana, en 1982, son relevante para porvenires contemporáneos del arte

${ }^{2}$ Dentro del catálogo de la exposición "Crónicas Americanas". Dibujos de José Bedia Valdés, realizada en la Galería de la Casa de la Cultura de Plaza, en febrero 28 de 1980, existe un texto de Gerardo Mosquera donde menciona cuestiones tan importantes como la siguiente:

"Bedia nos enseña aspectos del indio americano y su medio ecológico a través de imágenes documentales-fotoimpresos y fotocopiasofrecidas sin comentarios, de manera totalmente presentacional. Se busca, incluso, reforzar este carácter de testimonio mediante la inclusión, como parte del diseño, de renglones de escritura semejante a la de aquellos viajeros precursores de la arqueología americana, y de cuños del Archivo de Indias."

Este catálogo es editado por la Dirección de Artes Plásticas y Diseño del Ministerio de Cultura. Casa de la Cultura de Plaza. 
cubano. Un artista como Bedia no podía pasar por alto una cosa como esta en el trabajo del sistema de la imagen.

La propuesta de Bedia funciona a partir de la creación de un sistema visual con un elemento tipo categoría y todos los elementos subsecuentes como subcategorías, en un trabajo de elementos relacionales. En la obra Oyá en lo suyo, de 1998, esto puede distinguirse. Su trabajo posee "hilos comunicantes» y su interrelación es perdurable. El sistema bediano, constituido desde un aspecto jerárquico y viceversa, permite saber que todos los elementos contenidos en la imagen pertenecerán, en un estado absolutamente cíclico, los unos a los otros. El ir y venir es una correspondencia sistemática que abunda tanto en el pensamiento occidental como en el latinoamericano. Un ejemplo de esto podría ser el sistema en el que se inserta el pensamiento precolombino, considerado como circular por diferentes especialistas, entre los que se puede mencionar a Enrique Florescano, quien reflexiona sobre el concepto del eterno retorno: "[...] la creación y el ordenamiento del cosmos, el ritmo de la temporalidad cósmica, el final del mundo, la regeneración circular de las edades [...] esos tiempos diferentes no buscan explicar un acontecer, sino revelar la realidad sagrada que dio principio, organización y movimiento al universo" (Florescano 45).

Oyá en lo suyo no solo nos remite a la Oricha (diosa yoruba), sino a su propio concepto transversal en las diferentes prácticas culturales de origen africano, en las que su presencia simbólica aparece trabajando con lo que puede llamarse "cadena de representaciones» (Mitchell 20). Su obra se refiere al hábito, tanto africano como de los pueblos nativos americanos, de danzar con cantos que surgen distintos cada vez, puesto que los estados de trance y los distintos estados del cuerpo en el ritual permiten el nacimiento y la muerte de canciones y palabras. Este estado de renovación es también una forma de leer la obra bediana, en la genealogía planteada por Mitchell, y esto puede aludir a una imagen perceptiva. Las experiencias externas a la imagen gráfica y verbal, aquellas que son producidas por su quehacer religioso, y los estados transitorios que permiten acceder a otras imágenes, a otros espacios de la realidad, configuran distintas posibles conexiones que tendrán su propia lógica dentro del sistema bediano. La creación de su espacio visual es un lugar completamente abierto y su sistema, aparentemente cerrado en su circularidad, siempre puede permitir la existencia de otros elementos en el discurso de la imagen; no es una obra utópica, porque su obra no carece de lugar, sino que, todo lo contrario, es un «espacio absolutamente otro» (Foucault 22). 
En el sistema bediano los elementos se desafían por su extrañeza, su desconcierto en el origen y lo que los ubica fuera del orden. Bedia juega con la irregularidad de las palabras y las cosas que él ha clasificado nuevamente. Esto responde al camino entre Occidente y no Occidente en el que Bedia ha dirigido su producción y al propio carácter de su cultura, pasada por el filtro de lo transcultural. No le es extraño a Bedia interrelacionar la comunicación simbólica entre distintas prácticas tradicionales, como tampoco le será entre diferentes civilizaciones. Los paleros están comprometidos con el ámbito ritual, se saben extendidos en todas las posibilidades del pensamiento animista, ya que las cosas en el mundo no solo poseen una vida propia, sino que se encuentran en profunda relación, incluso en la idea de lo transfigurado, en la que un elemento natural o animal puede sustituir lo antropomorfo y viceversa.

Otro aspecto de la Regla de Palo, como también se le conoce, es que va unida al conocimiento del kikongo en Cuba, toda vez que este posee la característica de mezclarse con el español. En ese sentido, la imagen verbal puede aludir a conceptos que son totalmente abstractos y, por lo tanto, aquello que Bedia parece expresar como literal tiene contenidos enigmáticos. El uso de la palabra como imagen es una nueva forma de práctica social y cultural que se vincula a la obra bediana. Farris Thompson también ha mencionado que la construcción sintáctica de la palabra en su obra está relacionada con las canciones paleras, conocidas como mambos (Farris Thompson, Siluestas Sagradas 1), y que para ello utiliza una mezcla de nombres kikongo y palabras en español, los cuales a veces sencillamente no los combina, como en la obra Una vez tuve un amigo, del 2011. En el caso de la mezcla con las palabras en castellano, podemos mencionar la obra Kindembo Sarabanda Malongo Yaya arriba ntoto, del 2009, como un ejemplo muy claro de esto. La importancia del uso de los mambos descansa en la tradición de muchas culturas africanas, continuadas como herencia en las diásporas, de aconsejar y emitir sentencias o moralejas que tienen cierto carácter moral. Power ha mencionado que la preparación a la que Bedia fue sometido para la iniciación en la Regla de Palo tuvo una temporalidad de siete años y esto ha tenido un peso relevante.

Las expresiones pertenecientes a lenguas distintas, como en el caso de la instalación Mpangui jimagua, del 2000, enlaza el kikongo con el taíno, denotando, en ambos, la semejanza con el significado de hermano; aunque, también, la figura literaria del pleonasmo hace innecesaria la redundancia. Se debe conocer que la palabra jimagua, en lengua taína, refiere a dos elevaciones de tierra muy parecidas, y esta ha pasado al español cubano con el sentido de 
gemelo; por lo tanto, la repetición es útil porque reafirma la idea de «mi otro parecido». Ambas imágenes conforman en el sistema una reflexión sobre el propio concepto de jimagua. Esta analogía que parece, además, indicarnos una metáfora, por la comparación entre ambos, es más clara en la imagen pictórica. La metáfora como fenómeno lingüístico designa a las cosas por sus relaciones de similitud. Los dobles bedianos son la representación gráfica de una imagen perceptiva; las figuras se encuentran en relación con una idea o pensamiento, ubicado en un espacio visual totalmente fuera de todo espacio conocido. Cada obra bediana posee su propia taxonomía y sistema de representación, en el que se incluye el trabajo de la simetría bediana, producto de la observación de simetrías originarias, como el caso de la oceánica.

En la exposición Ante América, realizada a finales de octubre de 1992 por varios países, Bedia expone Espíritu del Arco, una obra con motivos recurrentes en la temática de la afrocubanidad y en la obra bediana, que asumirá conceptos universales y también muy localistas: la flecha y el número. Otros trabajos plantean similitudes formales y conceptuales con lo que llamaremos «número-motivo», como en ¿Adónde iremos? ¿Adónde no exista la muerte?³, donde, además, podemos distinguir la frase del poema metafísico de Nezahualcóyotl. Por otra parte, la historia de Centella Ndoki en el Palo Mayombe hace énfasis en el número nueve como un atributo, y, asimismo, explica que es madre de cuatro parejas de gemelos y un noveno hijo, Abikú, que es la encarnación de la muerte. Y, si bien esto parece responder al número nueve como un «motivo» en sí mismo, inquieta la direccionalidad de la flecha y sus fragmentaciones como posibles imágenes que rebasan la nominación de grafía o símbolo para dejarnos entrever otras cuestiones del sistema bediano, otros posibles motivos que rondan su image. Es frecuente en su trabajo el uso de otros elementos pictográficos que devienen en la condición distinta de la firma de "palero», que no es grafía ni símbolo, es un motivo único con características propias.

Es la firma en Palo Mayombe un atributo individual que parte de la "firma del mundo" conocida como "firma de los cuatro vientos". La firma del mundo es la "firma original" en la que se basa el conocimiento de esta práctica. Es una representación o grafía que se mueve hacia los cuatro puntos cardinales y que sostiene dentro de la cosmogonia de la Regla de Palo o Palo

${ }^{3}$ Esta obra puede revisarse en el siguiente enlace: http://www.artnet.com/artists/jos\%C3\%A9-bedia/ad\%C3\%B3nde-iremos-a-d\%C3\%B3nde-no-exista-la-muerte-nK4NTI5YobHIvWi6kjs_mw2. Revisado el día 27 de octubre de 2020. 
Mayombe el concepto de mapa del universo ${ }^{4}$. Es habitual en las "firmas» la direccionalidad, así como la fragmentación relacionada con firmas de mpungus ${ }^{5}$. En Lucero Viramundo existe la espiral o una condición centrípeta y centrífuga, que tiende al centro y a escapar de él. La tendencia en la firma de Mama Chola es la linealidad quebrada del centro con una dirección oblicua y vertical. Es en la firma de Centella Ndokien donde la circularidad representa un sistema rotativo, que corresponde a su aparente no-direccionalidad. Pero la condición individual de la firma tendrá variaciones en su pictografía, según el Palero y el ritual. Esta constante en el Palo Mayombe permite, entonces, comprender que el trabajo de lo que ahora denominaremos «elementos en la temática afrocubana contemporánea»-y, por tanto, en la obra de Bedia- se refiere a: flecha, flecha fragmentada, flecha numerada, número-números, que son leídos como motivos-«firmas» y motivos-«representaciones de deidades». Si el Mpungu Centella Ndoki es análogo al de la Oricha Oyá en la santería y en ambos casos, su número-atributo es el nueve, y, en ese caso, no estamos solo frente a una firma del Mpungu Centella, sino frente a la misma deidad.

En 1983, se presentó en Casa de las Américas un panorama muy amplio de la obra de Luis Camnitzer, en donde, a partir del diálogo con artistas y estudiantes de arte, se refirió a la necesidad de pasar de un "arte conceptual» a un "arte contextual» en Latinoamérica (Olivares, 2001), lo que marcó ciertas formas de presentar la visualidad en los artistas de la isla. La mirada de estos artífices contemporáneos cubanos hacia sí mismos, de una forma más amplia -más allá de los bordes de su isla-, asiente que puedan mirarse en otras consideraciones. Los elementos reiterados y referidos como «motivos» dentro de la temática de la afrocubanidad tomarán otros caminos hacia grafías y «firmas», que serán portadoras de significados nuevos. En este punto quisiera aclarar que la presencia visual de grafías y «firmas» pueden ser denotadas como modos de registro de esclavos negros en Cuba desde el siglo XIX; sin embargo, me parece oportuno referir que estos registros se realizaron en la técnica de la tinta sobre papel y son un antecedente importante para la construcción visual de estos posteriores «motivos» en la temática de la afrocubanidad.

\footnotetext{
${ }^{4}$ El palero, que es la forma de denominar al practicante de la Regla de Palo, solo puede serlo si este posee los conocimientos de esta práctica tradicional, es como puede realizar sus propias firmas dentro del ritual, que se basan en la estructura formal y conceptual de lo que se conoce como la firma del mundo o de cuatro vientos. Al poder realizar sus propias firmas obtiene los conocimientos que se le van dando a través de los muertos con los que establece una conexión.

${ }^{5}$ Se refiere en plural a deidades. Con ello se especifica que cada deidad tiene su propio catálogo de firmas.
} 
Es posible en la obra bediana también detectar este tipo de trazos y, en las frases, cierta insolencia del habla popular en Cuba, que parecen devenir de cromolitografías decimonónicas cubanas en las que se advierte una estructura clasificatoria de cierta interpretación de la imagen, a través de un léxico que en la época tenía una relación con la raza negra. Los otros aspectos atañen, por un lado, a la mirada hegemónica sobre nuestras propias construcciones del arte y, por el otro, a esa mirada que también ha sido de ida y vuelta, y que han establecido la construcción relacionada con image y picture en el arte contemporáneo latinoamericano.

Si la obra posmoderna está basada en lo estructuralista y lo posestructuralista, deja entonces entrever la sustitución y el nominalismo como fórmulas que desechan las posturas formalistas. Es en ese sentido que la narración pierde ante la pura visualidad. Esta es una herencia tácita del arte moderno que queda en la obra de José Bedia, ya que no solo se basa en «motivos» precedentes, sino en la sustitución de dichos motivos en la visualidad de su obra; esto es, un sistema de sustitución ya dado en el pensamiento africano: hombre-mujer-orichadioses-animal-planta-cosa-posesión en un estado que denominaremos gemelidad o jimagua, o la misma cosa donde la forma no importa o, más bien, la forma es un juego. La obra de Bedia remite tanto a Bedia en sí mismo como a todas las posibilidades de tiempos relativos, y, en ese punto, la iconología distingue estos «motivos» conectados que han sido o están en sustitución creando nuevas formas de nominalismo. Es por eso que pensar en el asunto de «el negro» en la pintura habla de la imposibilidad de que una grafía y una firma pudieran pertenecer a la muestra de «motivos» para las artes visuales en los principios del siglo XX cubano, que, al parecer, tampoco es considerada visualidad en la aparición de la temática, en 1943, con La jungla y La silla, de Lam, porque algunos de estos «motivos» son retomados de las influencias europeas, haitianas y de la plástica mexicana fundamentalmente.

De los puntos cardinales en la obra plástica de este artista son los caracteres o la narración formal primitivista en las que se ratifican los sistemas gráficos africanos y americanos. La relación entre imagen y texto en la obra bediana es una constante que nos lleva a pensar equivocadamente en lecturas enunciativas -es decir, una relación semántica-, pero otras veces no. Desde el punto de vista iconográfico, el artista ha recorrido motivos y géneros dentro de la historia del arte y los ha adecuado a su sistema. Podemos observar en su trabajo la presencia de los dioses aéreos. Oyá en lo suyo recuerda al dios Céfiro en El nacimiento de Venus de 
1484, obra renacentista de Sandro Botticelli, así como el género de las lidias, el paisaje, y estos regresos lo sitúan en la circunstancia de lo contemporáneo. De ahí su relación con la totalidad, con la inclusión, la intersección de discursos, sus sistemas transferibles y mutables. Este intercambio perenne no está relacionado con una propuesta global, su nominalismo es controlado, porque parte de la particularidad, no pluraliza y tampoco busca reflejar la realidad, más bien crea un nuevo orden de la imagen verbal y la imagen gráfica dentro de su trabajo visual (conectada con la mental y la perceptiva).

Las imágenes siempre tendrán un carácter ambiguo, pero se puede decir que la imagen bediana -cada fragmento de esta- es una hipótesis, y cada obra es la imagen de una tesis. Esta relación es contemporáneamente misteriosa. Los aspectos medievales de la búsqueda de lo sencillo, como el mejor modo de explicar las cosas, la clasificación renacentista, sobre todo en su intención de describir a las palabras en su estructura literaria, a las que aún se les nombra como figuras del lenguaje, entiéndanse: metáforas, hipérboles, pleonasmo, entre otros, y los ideogramas y conceptos africanos y nativos americanos. Estas son cuestiones que el artista cubano integra a su discurso, que funcionan dentro de un punto medio para crear nuevos vínculos a través de una taxonomía y sistema propios en cada obra. En fechas recientes, Juan Villoro ha planteado que estamos frente a «laboratorios» en donde los cuadernos de trabajo muestran "cosas para pensar»; es un modo en el que también podemos reflexionar la obra de Bedia. Este artista es también un precursor de estos procesos en los que el arte contemporáneo ronda: el mapa, el boceto y el objeto son el ocaso de una posibilidad, y crea, parafraseando al propio Villoro, "una isla dentro de una isla» ${ }^{6}$, que es analógicamente la creación de la image en su trabajo, una especie de ritualidad de la mirada. Esto explica por qué, en alusión a los antiguos códices mesoamericanos, su obra contiene la voluta o vírgula relacionada con la palabra y la intromisión gemelar de elementos anversos y conversos de algún ritual, o bien el hecho de que el elemento visual - pictográfico fundamentalmente- se muestre como la palabra misma creando ideogramas nuevos. Bedia se reconoce dentro de un espacio determinado por la «heteroclisis»; ese espacio es americano y es, a su vez, una forma de entender lo transcultural.

\footnotetext{
${ }^{6}$ Se pueden escuchar en la presentación del libro-homenaje a Gabriel Orozco en Bellas Artes, Ciudad de México en abril de 2013. https://youtu.be//Y83brlvlkQ. Revisado el día 28 de octubre de 2020.

${ }^{7}$ Es un término utilizado para el análisis de la iconografía mesoamericana que se puede también escribir: virgola cuando se intenta castellanizar. En esta ocasión usamos: voluta o vírgula. Tal expresión significa en la iconografía prehispánica la palabra o el canto, posee diversas formas de linea ondulada, pero siempre refiere a lo mismo.
} 
Para ello, se acerca a los comportamientos primarios de las prácticas culturales y fija desde esos órdenes, que pueden ser rituales, cosmogónicos y de pensamiento, una nueva disposición de las cosas.

\section{Referencias}

Bargna, Ivan. Arte Africano. Madrid: LIBSA, 2000. Impreso.

De Juan, Adelaida. "Presencia afrocaribeña en la pintura cubana moderna.» América sin nombre 19 (2014): 166-170. Impreso.

Florescano, Enrique. Memoria Mexicana. Ensayo sobre la reconstrucción del pasado: época prehispánica. D.F: Joaquin Mortiz, 1987. Impreso.

Farris Thompson, Robert. "Siluestas Sagradas.» Pascual Castillo, Omar. Estremecimientos. Granada: Anel Gráfica Editorial, Museo Extremeño e Iberoamericano de Arte Contemporáneo, Domus Artium 2002, Instituto de América/Centro Damián Bayón, 2002. Impreso.

Foucault, Michel. Las palabras y las cosas, una arqueología de las ciencias humanas. Trad. Elsa Cecilia Frost. $3^{\circ}$ edición. Ciudad de México: siglo veintiuno editores, 2015. Impreso.

Hernández, Orlando. "Introducción a una cosmografía.» Pascual Castillo, Omar. José Bedia obra, 1978-2006. Ed. Omar Pascual Castillo. Galería Ramis Basquet, 2007. Impreso.

Mosquera, Gerardo. "Persistencia del uso.» Persistencia del uso: José Bedia, instalaciones y dibujos. La Habana: Museo Nacional de Bellas Artes, Marzo de 1984. Catálogo. Impreso.

Power, Kevin. "José Bedia: una práctica de campo en el alma humana.» Pascual Castillo, Omar. José Bedia obra, 1978-2006. Ed. Omar Pascual Castillo. Galería Ramis Basquet Turner, 2007. Impreso.

Rosa Olivares y Asociados, S.L. Artistas Latinoamericanos 100 Latin American Artist. Ed. Rosa Olivares. Madrid: EXIT Publicaciones, 2001. Impreso.

Thomas Mitchell, W. J. Iconology. Image, Text, Ideology. Chicago: The University of Chicago Press., 1986. Impreso. 